\title{
INFLUENCE OF REMAINING CORONAL TOOTH STRUCTURE ON FRACTURE RESISTANCE OF ENDODONTICALLY TREATED MAXILLARY INCISORS
}

\author{
Ziad H. Rabie*
}

\begin{abstract}
Statement of problem. Although endodontically treated tooth is less likely to break when there is enough remaining tooth structure, controversy exists concerning the remaining coronal tooth structure of endodontically treated maxillary incisors.
\end{abstract}

Purpose. The aim of this investigation was to access the resistance to fracture of endodontically treated maxillary incisors with four walls and those with three walls of remaining coronal tooth structure and the influence of the site of the missing coronal wall.

Material and methods. Forty endontically treated maxillary central incisors were decoronated according to the criteria of each group, leaving $3 \mathrm{~mm}$ above the cemento-enamel junction (CEJ). A 0.5 -mm-wide chamfer was prepared $1 \mathrm{~mm}$ above the CEJ. The teeth were randomly divided into four groups $(n=10)$ Group 1 had four walls of coronal tooth structure (control group), whereas groups 2, 3, and 4 had only three walls, missing the labial, palatal, and mesial wall respectively (test groups). The cast dowel and cores and crowns $\mathrm{Ni}-\mathrm{Cr}-\mathrm{Be}$ base metal alloy were fabricated and cemented with Panavia 21 cement. A compressive load was applied 45-degree to the long axis with an Instron machine until failure at a crosshead speed of $0.5 \mathrm{~mm} / \mathrm{min}$. Failure load was recorded in $\mathrm{N}$ and data were analyzed with 1-way ANOVA, followed by multiple comparisons using Tukey HSD test $(\alpha=.05)$.

Results. The mean failure load $(\mathrm{N})$ of teeth with four walls $(965.7 \pm 37.7 \mathrm{~N})$ was significantly higher from teeth with three walls $(P<.001)$. The mean failure load of specimens without a labial wall $(675.1 \pm 38.9)$, was near that of teeth without a palatal wall $(692.7 \pm 36.3)$, and the mean failure loads of both groups were lower than those of teeth without a mesial wall $(713.4 \pm 35.7)$.. The mode of failure in the control group was a horizontal root fracture, whereas that of the test groups was either vertical or oblique fracture. The mode of failure in the control group was a horizontal root fracture, whereas that of the test groups was either vertical or oblique fracture.

Conclusions. Maxillary central incisors with four walls of remaining coronal tooth structure had significantly higher fracture resistance than teeth with only three walls. The site of the missing coronal wall did not influence the fracture resistance of endodontically treated teeth.

Clinical implications. Presence of remaining coronal tooth structure may be an important prognostic factor for endodontically treated maxillary incisors.

\footnotetext{
* Lecturer, Department of Fixed Prosthodontics, Faculty of Dentistry, 6 of October University, Egypt
} 


\section{INTRODUCTION}

Preservation of tooth structure is an imperative factor in the effective restoration of endodontically treated teeth. Previous studies have emphasized the amount of sound tooth structure remaining around the dowel ${ }^{1,2}$ and the coronal part. ${ }^{3}$ The remaining coronal tooth structure gives an unusual contact surface between the tooth and cast core, with result of increased retention of dowel and core, ${ }^{3}$ decreasing the stress transmission to the root, ${ }^{4-6}$ increasing the dowel length, and resisting dowel rotation. ${ }^{7}$ When the restored crown has a sound coronal tooth structure, four walls of coronal dentin remaining, and broadens very far past the margin of the core, there will be a ferrule effect. A ferrule is defined as a metal band or ring used to fit around the root or crown of a tooth. ${ }^{7}$ The advantages of the ferrule effect includes advancing embracing activity, prevent the shattering of the root ${ }^{8}$ lessening the wedging effect of tapered dowel, and opposing functional lever forces and the lateral forces applied amid dowel insertion. ${ }^{9}$

Endodontically treated teeth frequently lack coronal tooth structure because of caries, previous restorations, trauma, or endodontic treatment. In these conditions, successful reconstructing of an endodontically treated tooth may be a challenging technique. Endodontically treated teeth must have no less than $5 \mathrm{~mm}$ of tooth structure coronal to the crestal bone to ensure its functional life span. Of these, three millimeters are expected to keep up a sound soft tissue complex, and two millimeters of coronal tooth structure incisal to the preparation margin are important to ensure structural integrity. ${ }^{10}$ However, surgical crown lengthening or orthodontic extrusion of the tooth is required when remaining coronal tooth structure is less than 5 millimeters. The two techniques result in an acceptable increment in coronal tooth structure yet might be contraindicated in circumstances in which the crown-to-root ratio is compromised or where further exposure of tooth structure will have unfavorable esthetic outcomes.
As coronal tooth structure is increased by crown lengthening, the corresponding bony-supported tooth structure is reduced. This alter in the crown-to-root ratio may render the tooth less impervious to lateral forces. A 1:1 crown-to-root ratio has been suggested as the minimum ratio important for opposing lateral forces that may happen amid function. ${ }^{11}$ When a tooth has less than $50 \%$ of its coronal structure remaining, the use of a dowel-and-core is prescribed preceding prosthetic restoration. ${ }^{12}$ dowels can either be prefabricated or custom-made. Custom-made dowels and cores allow for a nearby adjustment of dowels to the post space preparations, and should fit optimally. ${ }^{13}$ The most widely recognized reason for failure for cast dowels and cores is dislodgment of dowel and root fracture ${ }^{10,14-16}$ However, pre-fabricated dowels have an advantage in that the dowel space can be prepared and the dowel bonded in a single visit.

The cervical zone of a complete crown restoration acts as a ferrule when encircling axial tooth structure between the core and preparation margin. The minimum effective ferrule ought to have 1.5 millimeters of coronal dentin above the crown margin..$^{17,18}$ If a ferrule is not obtained, the tooth is at risk of fracture regardless of what types of dowel and core are used..$^{11,19}$ Occasionally, the coronal tooth structure might be damaged to the point that an ideal ferrule can not be made.

Libman and Nicholls ${ }^{20}$ demonstrated that 1.5 millimeters of axial wall height significantly improved endodontically treated teeth restored with cast dowels and cores and complete crowns. For endodontically treated teeth restored with prefabricated dowels, composite resin cores, and complete crowns, $\mathrm{Ng}$ et $\mathrm{al}^{21}$ showed that 2.0 millimeters of axial wall height increased their fracture resistance. Others, ${ }^{22,23}$ however, have revealed that the presence of remaining coronal tooth structure between the core and preparation margin was more important for fracture resistance of endodontically treated teeth than dowel length and type. Also, other investigators ${ }^{24,25}$ have 
demonstrated that the presence of tooth structure coronal to the preparation margin does not enhance the fracture resistance of endodontically treated teeth. Patel and Gutteridge ${ }^{26}$ including endodontically treated teeth restored with cast dowels and cores without coronal restorations and absence of the ferrule effect, the presence of coronal tooth structure between the core and preparation margin did not fortify the tooth. Moreover, Al-Hazaimeh and Gutteridge ${ }^{25}$ exploring prefabricated dowels and composite resin cores with complete crowns failed to show a difference between restored endodontically treated teeth with or without remaining coronal tooth structure between the core and preparation margin. Patel and Gutteridge $^{26}$ showed that remaining coronal dentin will not strengthen a tooth restored with a cast dowel and core. There was no statistically significant difference in the strength of a dowel with cores in teeth with lingual dentin or buccal and lingual dentin when compared to teeth without coronal dentin. Teeth with buccal coronal dentin were significantly less fracture resistant than teeth without coronal dentin. However, Al-Wahadni and Gutteridge ${ }^{27}$ demonstrated that coronal buccal dentin improved the fracture resistance of teeth restored with dowel and cores when compared with teeth without coronal dentin. Both studies were performed without a covering crown, which did not reproduce the clinical situation of a crown with a ferrule.

Therefore, the purpose of this in-vitro study was to compare the fracture resistance of endodontically treated teeth with four walls and those with three walls of remaining coronal tooth structure and demonstrate the effect of the site of the missing coronal wall. The null hypothesis was that teeth with four walls of remaining coronal dentin would have no significant higher fracture resistance than teeth with three walls of remaining coronal dentin. Moreover, the site of the missing coronal wall would have no effect on the fracture resistance of endodontically treated teeth restored.

\section{MATERIAL AND METHODS}

Forty intact recently extracted human maxillary central incisors were scraped clean of remnants of periodontal ligaments and examined stereoscopically at $10 \times$ to verify the absence of caries, restorations, and fractures. Initial silicone index for each tooth was made with putty poly(vinyl siloxane) (GC America Inc., Chicago, Il.).

The root length and the labial-palatal and mesial-distal width were measured by a vernier caliper (Model 93218-0654, Harbin Measuring and Cutting Tool Group Co. Ltd. Harbin PR China) at the labial midpoint of the cemento-enamel junction level. All teeth were randomized into three test and one control groups $(\mathrm{n}=10)$. ANOVA was used to determine the significant difference among the groups $(p>.05)$. The teeth were stored in distilled water with $0.1 \%$ thymol disinfectant (Mallinckrodt Baker, Phillipsburg, NJ) at room temperature.

Access to the root canals was gained with diamond rotary cutting instruments (Brasseler USA, Savannah, GA). Canals were endodontically instrumented. All teeth were held by hand during instrumentation, and the plane of greatest curvature was aligned parallel to the plane of the file oscillation. Each canal was enlarged manually by a single operator until an ISO size 15 file (K-flex, Kerr, Romulus, MI) could be inserted to the working length of $13 \mathrm{~mm}$ (1 mm above the apical foramen) with K-files. ${ }^{28}$ The canals were prepared with a ProTaper (Bisco, Schaumburg, IL) rotary system (X-smart, Ref A 1004) according to the manufacturer's instructions, using s1 and s2 shaping files, followed by f1, f2, and f3 finishing files. Each canal was irrigated with $2 \mathrm{~mL}$ of $15 \%$ ethylenediaminetetraacetic acid (EDTA enlargement; Produits Dentaires, Vevey, Switzerland) irrigating solution when there was a file size change and after filing was complete. This was accomplished using a syringe fitted with a 27 -gauge needle placed passively in the coronal canal opening. The maximum 
depth of placement of the needle tip was 1-2 mm incisal to the apical foramen. During irrigations, specimens were held vertically, apices down, to ensure apical penetration of irrigant solutions. After the last irrigation, canals were completely dried with matching color-coded paper points (ProTaper Paper Points, Ref A 022W).

Canals were obturated with a gutta-percha cone (ProTaper Gutta Percha Points, Ref A 022X) matching the last file used to prepare the apical third of the canal to the working length and eugenol-free epoxyamine resin sealer (AH Plus sealer; Dentsply DeTrey, Konstanz, Germany). Lateral condensation using a finger spreader and fine accessory guttapercha points (Dentsply DeTrey) was performed until the canals were completely obturated. Extracoronal excess of gutta-percha was removed using heated condenser (Paiva;Duflex SS White,Rio de Janeiro, Brazil). After 24 hours, gutta-percha was then removed from each root canal to a point $5 \mathrm{~mm}$ from the apex using a Gates-Glidden burs (Dentsply Maillefer) with a plastic stop leaving specimens with $8.0 \mathrm{~mm}$ dowels space length. Again, each dowel space was rinsed with $10 \mathrm{~mL}$ of the EDTA irrigant for 30 seconds to remove any remaining sealer. Irrigating solutions were removed from the canal with sufficient paper points to completely dry the canal surface. A radiograph was taken to confirm complete removal of gutta-percha and sealer remnants.

A dowel space was prepared in each tooth to a standardized length of $8 \mathrm{~mm}$. The length of the dowel space was verified with a periodontal probe fitted with an endodontic reference stop and a radiograph. Crowns of all specimens were sectioned perpendicular to the long axis with a 0.15 diamond wafering blade (Buehler, Lake Bluff, IL) in an Isomet 1000 slow-speed saw (Buehler) leaving $3 \mathrm{~mm}$ above the CEJ. A 0.5 -mm-wide chamfer using a round end tapered diamond bur (FG D16, Intensiv SA) under water spray was prepared $1 \mathrm{~mm}$ above the CEJ. Teeth in the group 1 (control) were prepared as mentioned above while teeth in groups 2, 3, and 4 (test groups), labial, palatal, and mesial walls respecwere eliminated respectively, until the heights of these walls were $1 \mathrm{~mm}$ above the CEJ.

Dowel and core patterns were fabricated with autopolymerizing acrylic resin (Dura Lay, Dental Mfg.C., Wort,Il) and plastic burnout dowel (Swedish Dental Supplies, Sweden) using the initial silicone indices for each tooth to ensure uniform thickness of the full metal crowns. Each dowel and core pattern was invested and cast with $\mathrm{Ni}-\mathrm{Cr}-\mathrm{Be}$ base metal alloy (Rexillium III, Pentron, Wallingford, CT) meeting American Dental Association specifications for alloy system. The casting dowels were adjusted with a fit checker (Fit checker, GC) until dowels and cores were fully seated, and their fitness become passive. Radiographs of each tooth was made to verify complete seating. Cast dowel and cores were cemented with Pabavia 21 cement (Kuraray Co, Ltd., Osaka, Japan) using a lentulo spiral (Mani, Tochigi, Japan), seated gently using pumping action to release the hydraulic back pressure and held with finger pressure for 5 minutes. Excess cement was carefully removed using tapered diamond bur.

Each tooth was mounted on a surveyor and prepared for a complete cast crown with $0.5 \mathrm{~mm}$ chamfer finish line using a high-speed diamond rotary cutting instrument (6856 L-016; Brasseler) and water spray. The preparations ended on the level of the core build-up without ferrule effect to enable the load force to be transferred from the restoration to the root structure..$^{31}$ A single-mix technique was used to make impressions of the prepared teeth with poly(vinyl siloxane) (Examix, GC America Inc), and cast with type IV die-stone (Jade stone, Whip Mix Corp., Louisville, KY). Two coats of die spacer (Tru Fit; George Taub Products and Fusion, Jersey City, NJ) were applied to the axial surfaces of each die $1 \mathrm{~mm}$ short of the finish lines. Wax copings (Gator Wax, Whip Mix Corp) were fabricated for each die using each initial silicone index. A marking 
line was scraped $2 \mathrm{~mm}$ below the incisal edge of each wax pattern on the palatal surface. A palatal step design $0.3-\mathrm{mm}$ deep and 1-mm wide was formed on each specimen to standardize the position of the loading device during testing. The patterns were invested with phosphate-bonded investment (Cera-Fina, Whip Mix Corp.) and cast with ADA base metal alloy (Rexillium III, Pentron). Castings were recovered from investment, bench-cooled to room temperature, cleaned in pickling solution (JetPac; JF Jelenko Co, Armonk, NY), and air-porn particle abrasion with $50 \mu \mathrm{m}$ aluminum oxide for 10 seconds with contra-angle microetcher (model erc-er; Danville Engineering, Danville, CA) at 60 psi. To minimize the effect of variations in the casting procedure, the same clinician completed all castings. The internal surface of each casting was inspected with a $20 \times$ stereomicroscope. After necessary adjustment, crowns were cemented to their respective preparations with Panavia 21 cement (Kuraray Co) according to the manufacturer's instructions. The specimens were then placed in $100 \%$ humidity for 24 hours at $37^{\circ} \mathrm{C}$.

To simulate the periodontal ligament, each root was covered to within $1 \mathrm{~mm}$ of the CEJ with a thin layer (approximately 0.1 to $0.2 \mathrm{~mm}$ ) of wax (GatorWax), and was embedded in a plastic ring (60-mm diameter, 20-mm high) with epoxy resin (Epoxide Resin; Leco Corp., St. Joseph, MI). The set was immersed in water at $75^{\circ} \mathrm{C}$ for 1 minute to remove the wax layer, leaving a space between the root and the epoxy resin. An addition-cured silicone rubber (Speedex; Coltene/Whaledent Inc, Cuyahoga Falls, $\mathrm{OH}$ ) was manipulated and coated on the surface of the roots, which were repositioned into the epoxy resin blocks. After polymerization, excess impression material was removed with a surgical blade. Roots with periodontal membrane simulation were mounted and secured in epoxy resin blocks with plastic rings. With a special mounting jig, each specimen was positioned in the mounting device and aligned at a $45^{\circ}$ angle with respect to the long axis of the tooth. A unidirectional static load was then applied with a 1-mm diameter steel bar, beveled $45^{\circ}$ at the terminus using a universal load-testing machine (Instron 4204; Instron Corp, Canton, MA) in the compression mode with a crosshead speed of $0.5 \mathrm{~mm} / \mathrm{min}$ to the locating groove in the palatal concavity of the crown and at an angle of $135^{\circ}$ from the long axis of the root. This angle approximated the present palatal angle between the long axis of the maxillary and mandibular central incisors. ${ }^{28}$ Failure load was recorded from a force deflection curve, and mode of failure was determined by visual inspection of all specimens. Means and standard deviations were calculated for each group, and results were analyzed with one-way ANOVA and Tukey's Honestly Significant Difference (HSD) test $(\alpha=0.05)$.

\section{RESULTS}

Represents the labial-palatal and mesial-distal (Table 1) width measured at the labial midpoint of the cementoenamel junction level, and root lengths measured from the apex to that level. There were no significant differences in the dimensions between the four groups.

TABLE (1) Mean dimensions (mm) of randomly assigned maxillary central incisors in each group $(n=10)$

\begin{tabular}{lccc}
\hline Group & Root length & Labial-palatal & Mesial-distal \\
\hline 1 & $13.4 \pm 0.9$ & $6.3 \pm 0.3$ & $7.1 \pm 0.4$ \\
2 & $13.1 \pm 0.6$ & $6.3 \pm 0.4$ & $7.2 \pm 0.4$ \\
3 & $13.3 \pm 0.9$ & $6.2 \pm 0.5$ & $7.2 \pm 0.4$ \\
4 & $13.2 \pm 0.7$ & $6.3 \pm 0.3$ & $7.2 \pm 0.3$ \\
F-value & 0.53 & 0.75 & 0.81 \\
P-value & 0.37 & 0.13 & 0.51 \\
\hline
\end{tabular}

Group 1 (control) has four walls; group 2, labial wall eliminated; group 3, palatal wall eliminated; group 4, mesial wall eliminated. 
The mean and standard deviations of the failure load $(\mathrm{N})$ for all tested groups are shown in figure 1. Pairwise comparisons with the Tukey test in Table 2 Showed the mean failure load of teeth with four walls $(965.7 \pm 37.7 \mathrm{~N})$ was significantly higher from teeth with three walls $(P<.001)$. The mean failure load of specimens without a labial wall $(675.1 \pm 38.9)$, was near that of teeth without a palatal wall $(692.7 \pm 36.3)$, and the mean failure loads of both groups were lower than those of teeth without a mesial wall (713.4 \pm 35.7$)$. Teeth failed differently, the failure mode within the control group was horizontal root fracture at the middle part of the root, whereas the majority of fractures in the test groups were vertical fractures extending from the dentin-core junction of the buccal surface down to the lingual surface. The mode of failure is presented in Table 3

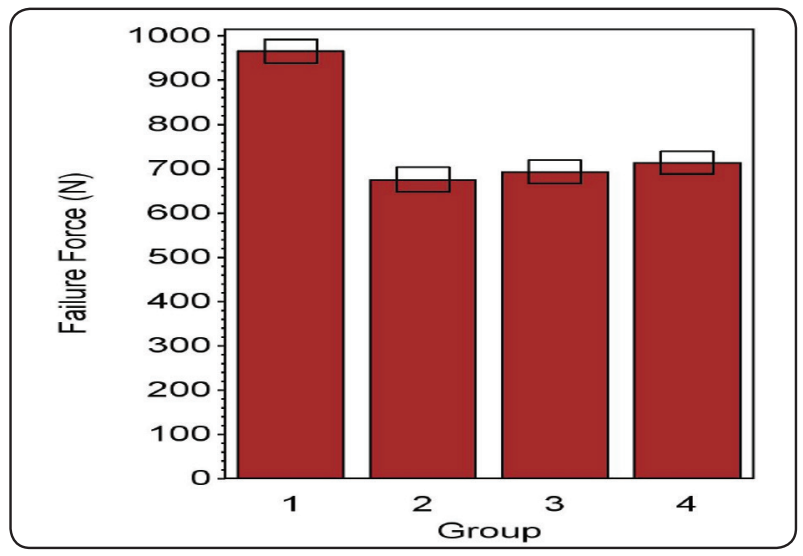

Fig. (1) Mean and standard deviations of the failure load (N) for all tested groups.

TABLE (2) One-way ANOVA for control and test groups.

\begin{tabular}{lccccc}
\hline $\begin{array}{l}\text { Source of } \\
\text { variations }\end{array}$ & $d f$ & $\begin{array}{c}\text { Sum of } \\
\text { Squares }\end{array}$ & $\begin{array}{c}\text { Mean } \\
\text { Square }\end{array}$ & F value & $p$ \\
\hline Model & 3 & 562147.7 & 187382.6 & 135.4 & $<.001$ \\
Error & 36 & 49817.9 & 1383.8 & & \\
Corrected total & 39 & 611965.6 & & & \\
\end{tabular}

TABLE (3) Failure mode of teeth included in the study.

\begin{tabular}{|l|c|c|c|c|}
\hline \multicolumn{1}{|c|}{ Mode of failure } & Group 1 & Group 2 & Group 3 & Group 4 \\
\hline $\begin{array}{l}\text { Horizontal cervical } \\
\text { root fracture }\end{array}$ & 2 & 2 & \\
\hline $\begin{array}{l}\text { Horizontal middle } \\
\text { root fracture }\end{array}$ & 7 & 3 & 6 & 3 \\
\hline $\begin{array}{l}\text { Horizontal apical } \\
\text { root fracture }\end{array}$ & $\begin{array}{l}\text { Vertical root } \\
\text { fracture }\end{array}$ & & & \\
\hline $\begin{array}{l}\text { Horizontal and } \\
\text { vertical root } \\
\text { fracture }\end{array}$ & & & & 7 \\
\hline
\end{tabular}

Group 1 (control) has four walls; group 2, labial wall eliminated; group 3, palatal wall eliminated; group 4, mesial wall eliminated.

\section{DISCUSSION}

The data support rejection of the null hypothesis of the study that teeth with four walls of remaining coronal tooth structure would have no significant higher fracture resistance than teeth with three walls of remaining coronal dentin. Moreover, the site of the missing coronal wall would have no effect on the fracture resistance of endodontically treated maxillary incisors restored. The idea of incorporating a ferrule effect to the tooth' fracture resistance has been presented..$^{10,17,18}$ The ferrule can distribute the stress concentrations at the junction between the tooth and crown margin passing through the remaining coronal tooth structure above the crown margin..$^{11,19-22}$ However, there are numerous clinical circumstances where it isn't conceivable to build a perfect ferrule. The current study compared the fracture resistance of endodontically treated teeth with three walls and those with four walls of coronal tooth structure without incorporating a ferule effect. The three walls of coronal tooth structure were selected because it represents the clinical situations. The present investigation imitated manufactured crowns without a ferrule effect. ${ }^{14,15}$ The mean failure 
load of this examination was more noteworthy than those of previous investigations. It is plausible that the results of the fracture resistance would not be the result of the embracing action from a ferrule effect. There was no statistically significant difference between the mean value in each group of central incisors used in each group of the study. The dowel length of $8 \mathrm{~mm}$ in this study, which approximates the clinical crown length, was similar that used by several investigators..$^{14,15,28}$-The dowels and crowns were manufactured with $\mathrm{Ni}-\mathrm{Cr}$ alloy due to its high modulus of elasticity, which transfers stress to the remaining tooth structure resulting in a more harming effect. Results of the current study demonstrated that the fracture resistance of a specimens with four walls of coronal tooth structure was significantly higher than that with three walls of coronal tooth structure. Possible explanation is that the strength of the tooth is directly related to the amount of tooth structure since force distribution in root became more favorable when coronal tooth structure was retained. ${ }^{4-6}$ Moreover, it can likewise give an irregular joining between cast and tooth, adding to an increased retention and resistance of the dowel. ${ }^{7}$ Accordingly, coronal tooth structure ought to be preserved whenever possible ${ }^{9}$

The remaining tooth structure is the most significant factor in determining tooth strength..$^{28-32}$ Compared to an undamaged tooth with a vital pulp, the structural integrity of an endodontically treated tooth is compromised. It is necessary to retain as much coronal tooth structure as possible during restorative procedures, as teeth with little remaining coronal tooth for structural support are less able to withstand functional and impact stresses. ${ }^{32}$ In the current study, teeth without a labial wall had the lowest fracture resistance among the tested groups, and teeth without a mesial wall had a tendency to have minimal impact on fracture resistance. This finding is in agreement with the majorities of reported studies..$^{24,25}$ The failure mode of the tested groups was only catastrophic root fracture which could not be retrieved as a result of restoring with cast dowel and core. Specimens within the control group exhibited horizontal root fracture at the midroot level, while teeth within the experimental groups presented vertical root fracture. This clarification may identify with the extension of a crown margin completely surrounding the cervical part of the tooth.

In the current study, teeth specimen with similar morphology and mesiodistal and labiopalatal dimensions were used. There were some limitations in this study. The ferrule effect was not included in this study to enable the load force to be transferred from the restoration to the root structure. Though the test method used in this study attempted to simulate the clinical situation, the unidirectional static loading force applied did not replicate the complex dynamic forces present in the oral environment during mastication and with parafunctional habits; however, a unidirectional static loading force was selected in this study and in many other studies of root fractures to minimize the experimental variables. ${ }^{33,34}$ Clinically, root fractures in maxillary anterior teeth restored with dowel-cores and artificial crowns are more likely to occur from cyclic fatigue than single severe impacts. Further laboratory testing should more closely simulate these two factors. The angulation between the long axes of the anterior teeth also can significantly affect the in vitro loading forces required for the fracture of dowel-core restored roots. ${ }^{32}$

\section{CONCLUSIONS}

Within the limitations of this study, the following conclusions can be drawn:

1. The more the remaining coronal tooth structure, the more the increase the guard against fracture under occlusal load. Teeth with four walls of remaining coronal tooth structure were more resistance to fracture than teeth with three walls of remaining coronal tooth structure. 
2. Fracture resistance of endodontically treated maxillary incisors restored with dowel-corecrown did not influenced by the site of the missing coronal wall..

3. Teeth with four walls of remaining coronal tooth structure fractured horizontally at the mid-root level, whereas teeth with three walls of remaining coronal tooth structure mostly showed vertical root fracture.

\section{REFERENCES}

1. Trabert KC, Caputo AA, Abou-Rass M: Tooth fracture a comparison of endodontic and restorative treatments. J Endod 1978;4:341-6.

2. Caputo AA, Standlee JP: Pins and posts why, when and how? Dent Clin North Am 1976;20:299-31.

3. Tjan AH, Whang SB: Resistance to root fracture of dowel channels with various thickness of buccal dentin walls. J Prosthet Dent 1985;53:496-500.

4. Henry PJ: Photoelastic analysis of post core restorations. Aust Dent J 1977;22:157-9.

5. Hunter AJ, Flood AM: The restoration of endodontically treated teeth: Part 2. Posts. Aust Dent J 1989;34:5-12.

6. Hunter AJ, Flood AM: The restoration of endodontically treated teeth: Part 3. Cores. Aust Dent J 1989;34:115-21.

7. McKerracher PW: Rational restoration of endodontically treated teeth: 1. Principles, techniques and materials. Aust Dent J 1981;26:205-8.

8. Rosen H: Operative procedures on mutilated endodontically treated teeth. J Prosthet Dent 1961;11:973-86.

9. Sorensen JA, Engelman MJ: Ferrule design and fracture resistance of endodontically treated teeth. J Prosthet Dent 1990;63:529-36

10. 10. Spear F. When to restore, when to remove: the single debilitated tooth. Compend Contin Educ Dent 1999; 20: 316-28.

11. Rosenstiel SF, Land MF, Fujimoto J. Contemporary fixed prosthodontics. 5th ed. St Louis: Elsevier; 2015. p. 336978.

12. Christensen GJ. When to use fillers, build-ups or posts and cores. J Am Dent Assoc 1996;127:1397-8.
13. Qualtrough AJ, Mannocci F. Tooth-colored post systems: a review. Oper Dent 2003;28:86-91.

14. Turner $\mathrm{CH}$. The utilization of roots to carry post-retained crowns. J Oral Rehabil 1982;9:193-202.

15. Sorensen JA, Martinoff JT. Intracoronal reinforcement and coronal coverage: a study of endodontically treated teeth. $\mathrm{J}$ Prosthet Dent 1984;51:780-4.

16. Sorensen JA, Martinoff JT. Endodontically treated teeth as abutments. J Prosthet Dent 1985;53:631-6.

17. The glossary of prosthodontic terms. 8th ed. J Prosthet Dent 2005;94:38

18. Libman WJ, Nicholls JI: Load fatigue of teeth restored with cast post and cores and complete crowns. Int J Prosthodont 1995;8:155-61.

19. Goldstein RE. Esthetics in Dentistry. 2nd ed. Hamilton: Decker; 2002. p. 525-98

20. Libman WJ, Nicholls JI. Load fatigue of teeth restored with cast posts and cores and complete crowns. Int J Prosthodont 1995;8:155-61

21. Ng CC,Al-Bayat MI, Dumbrigue HB, Griggs JA, Wakefield $\mathrm{CW}$. Effect of no ferrule on failure of teeth restored with bonded posts and cores. Gen Dent 2004;52:143-6.

22. Isidor F, Brondum K, Ravnholt G. The influence of post length and crown ferrule length on the resistance to cyclic loading of bovine teeth with prefabricated titanium posts Int J Prosthodont 1999;12:78-82.

23. Milot P, Stein RS. Root fracture in endodontically treated teeth related to post selection and crown design. J Prosthet Dent 1992;68:428-35.

24. Patel A, Gutteridge DL. An in vitro investigation of cast post and partial core design. J Dent 1996;24:281-7.

25. Al-Hazaimeh N, Gutteridge DL. An in vitro study into the effect of the ferrule preparation on the fracture resistance of crowned teeth incorporating prefabricated post and composite core restorations. Int Endod J 2001;34:40-6.

26. Patel A, Gutteridge DL: An in vitro investigation of cast post and partial core design. J Prosthet Dent 1996; $24: 281-7$

27. Al-Wahadni A, Gutteridge DL: An in vitro investigation into the effects of retained coronal dentine on the strength of a tooth restored with a cemented post and partial core restoration. Int Endodon J 2002;35:913-8. 
28. Ayad MF, Ibrahim LA, Rashid RG. Influence of dowel type on push-out bond strength to regional root canal dentin. Am J Dent 2012;25:307-12.

29. Goncalves L, Vansan L, Panlino S, et al: Fracture resistance of weakened roots restored with a transilluminating post and adhesive restorative materials. J Prosthet Dent 2006;96:339-44.

30. Wu X, Chan AT, Chen YM, et al: Effectiveness and dentin bond strengths of two materials for reinforcing thin-walled roots. Dent Mater 2007;23:479-85.

31. Marchi GM, Paulillo LA, Pimenta LA, et al: Effect of different filling materials in combination with intraradicular posts on the resistance to fracture of weakened roots. J Oral Rehabil 2003;30:623-9.

32. Loney RW, Moulding MB, Ritsco RG: The effect of load angulation on fracture resistance of teeth restored with cast post and cores and crowns. Int J Prosthodont 1995;8:247-51.

33. Newman MP, Yaman P, Dennison J, et al: Fracture resistance of endodontically treated teeth restored with composite posts. J Prosthet Dent 2003;89:360-7.

34. Mitsui FH, Marchi GM, Pimenta LA, et al: In vitro of fracture resistance of bovine roots using different intraradicular post systems. Quintessence Int 2004; 35:612-6. 